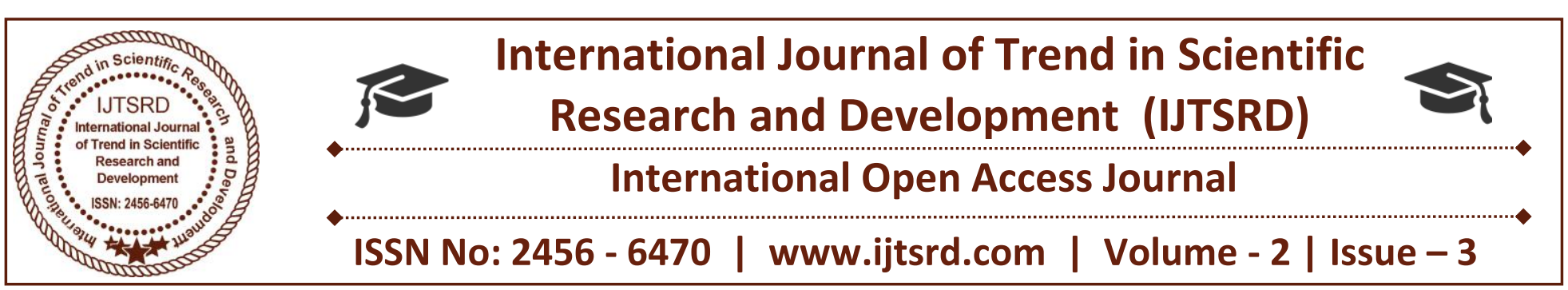

\title{
Career Tracking
}

\author{
Mohana Priya. A ${ }^{1}$, Thafsil Rahman. K. $\mathbf{M}^{\mathbf{2}}$, Sri Abilesh Kumar. $\mathbf{T}^{\mathbf{3}}$, Sakthinathan. $\mathrm{S}^{\mathbf{4}}$ \\ Department of Computer Science and Engineering, \\ ${ }^{1}$ Assistant Professor, Sri Shakthi Institute of Engineering and Technology, Coimbatore, India \\ ${ }^{2,3,4}$ B.E Scholar, Sri Shakthi Institute of Engineering and Technology, Coimbatore, India
}

\begin{abstract}
Now a days, filtering the students for the placement drive is too difficult task to manage the student's record. To overcome these difficulties the concept CAREER TRACKING is implemented. It is to track the student's eligibility to attend the Recruitment process of company, based on their attendance, Mock Periodical Technical Test and Mock Periodical Aptitude Test percentage. In this web application we will have the database of the companies which came to our college which includes company's package's, sample interview question which have been asked in the last recruitment. Also it includes, the feedback and preparation methodologies to attend the interview by the aluminise. It gives an accurate view of the student's performance and their placement status.
\end{abstract}

Keywords: career tracking, placement, test, interview, courses, web application.

\section{INTRODUCTION}

Career tracking is used to track the student's performance by conducting the test for the recruitment process. It is a web application that is exclusively given for college management to maintain the student database. The management will maintain the database by updating their attendance and conducting assessment for the students in online. The company which approach the college for placement drive will have the certain criteria about students mark in university. The management filters the students using this application and the information about the Company date and time of the recruitment process will be updated to the student's e-mail for the awareness. Additional to this, the students who appeared for any particular company will upload the feedback to this web portal where the students who take mock test of that company will view that to prepare accordingly.

\section{WORKING}

The web application contains two login pages one for the student and another for the admin. This can be logged in by the student or the admin who already registered. The registered student can go to their respective account and can update their personal information, along with their marks obtained from School and the University. The management (admin) will enter into their respective login to maintain the student's details, even the management can upload their details so it can be a good understanding with the students. The attendance of the respective student can be maintained so the management can track the students according to the management way. The details of the companies that have already visited to the institution, and the count of the respected students who all got selected by the company is maintained in the database.

Then the students appeared for the recruitment process can upload their feedback to the web about the experience of the recruitment process, where this helps the student to know more and prepare accordingly. In the recruitment once the company decided to visit the institution with their criteria the management filters the student according to the company criteria and send a notification to the respective students with the name of the company, company description, time date and venue of the 
placement drive. This increases the student's dedication.

The students get the notification for attending the company drive to their e-mail once the student accept their details will be conformed and if not then it will be removed. The final list will be calculated at end.

Apart from this, in this web application a module named as MY COURSES is given here the management can attach or upload the respected materials which is useful to the students for their preparations. In this application conducting exam is another part. The management can conduct the exams at any time. And score of each student is stored and viewed by the management. According to this the management can guide the student by giving them more materials and activities.

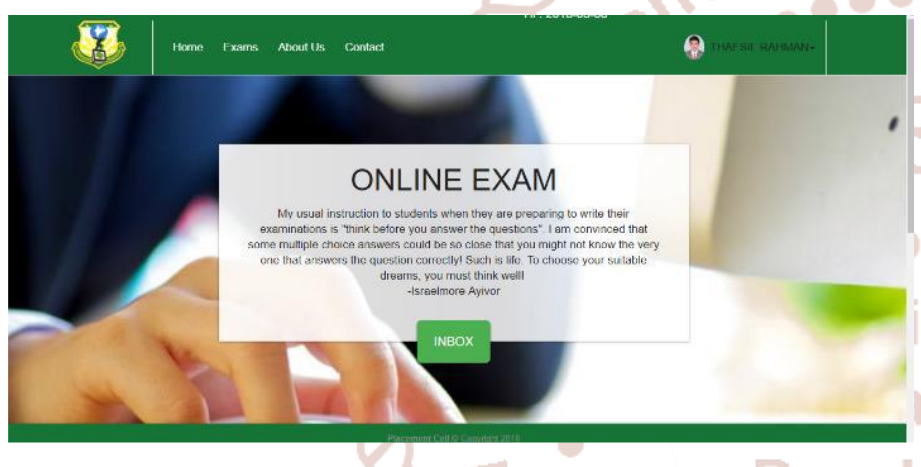
(8)

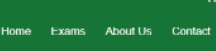
Q

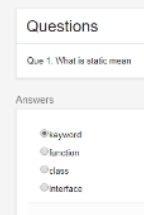

NEXT OUIESTION

\section{ADDITIONAL FEATURES}

The assessment deals with the student performance regarding the further placement they are going to attend. Additional to it the student attendance also been updated to it. This make the easy maintenance of the student attendance management. And the notification regarding the placement drive will be automatically sent to the students for their awareness. The notifications are in two ways

1. The notification which is send can be viewed by all the students since it is appeared in the dashboard.

2. The notification is send only to particular student. So according to the given notification the student can be prepared.

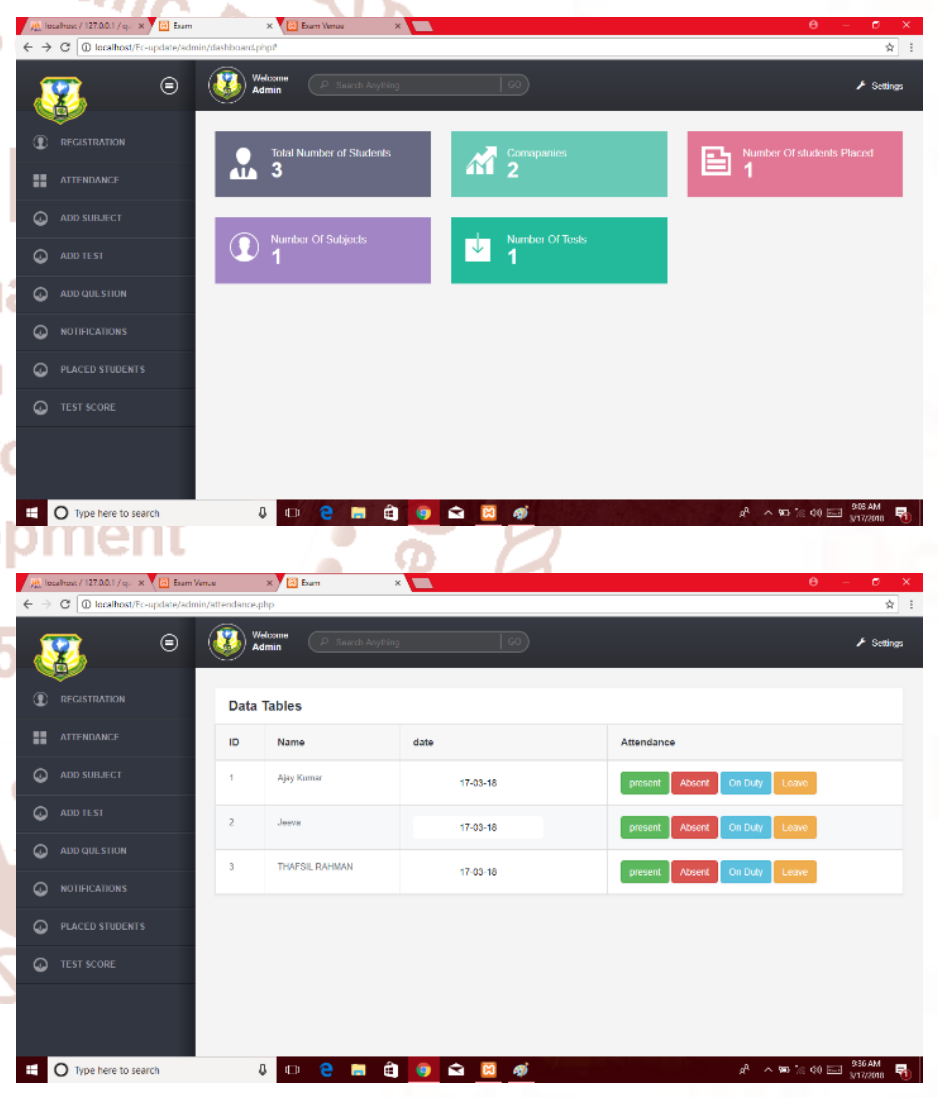

Maintaining attendance is the only way to know whether the students are engaged with the class or not. By knowing the attendance percentage of the student the management can decide whether student is allowed to attend the company's recruitment process. 


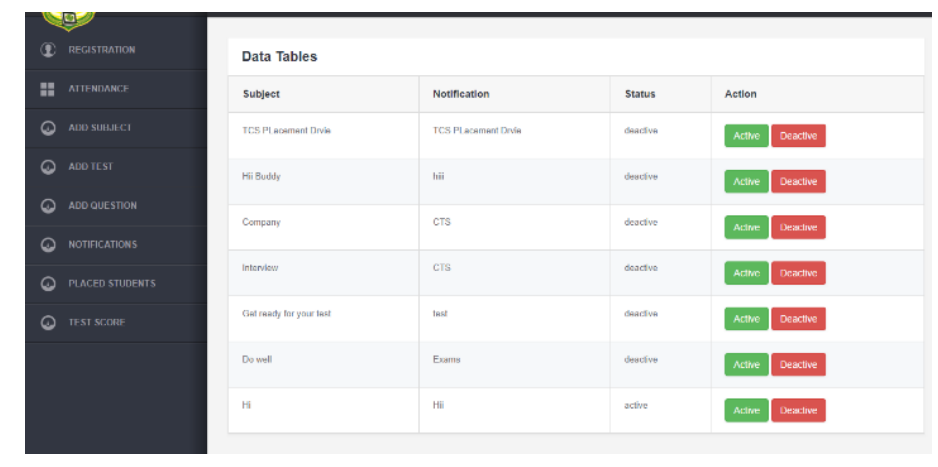

\section{TECHNOLOGY USED}

The front end is developed using the software called as Dreamweaver and bootstrap, database connectivity is done in Php, the backend is developed in Xamp. These are the common technology that been used to develop the web application. In the Dreamweaver we have coded languages like HTML (For the front end development), CSS (For the style), and PHP (For the database connectivity). The Xamp is used for the database creation bye coding MySQL so that we can store the data in the database since it is connected to the database.

\section{CONCLUSION}

This application can be implemented for the right path for the career. This can be very useful to the both management and students who are opt to the placement. The institute can also make an easy way for the students to go for the right company with their ability. This can make an impact for the future who decide to join to their respective field with the right path.

\section{FUTURE ENHANCEMENT}

In this application we can add many features like voice note, QR code for attendance registration, and student's marks can be displayed as a pie chart.

\section{REFERENCES}

1) Fagbola T. M., Adigun A. A., Oke A. O. (2013), "Computer-Based Test System For University academic enterprise examination". International Journal of Scientific \& Technology Research volume 2, issue 8, august 2013.

2) J. Wen, Y. Zang, S. Xia, Y. Yan, "A web-based examination system based on PHP+Mysql", Engineering in Medicine and Biology Society 2005. IEEE-EMBS 2005. 27th Annual
International Conference of the, pp. 2882-2885, 2005.

3) Leibowitz, B., Farren, C., \& Kaye, L. (1986). Designing career development systems. San Francisco: Jossey-Bass.

4) Liu, X.: The research on online examination system. Science and Technology Information of Heilongjiang Province 22(10), 176-178 (2008).

5) S. Chao, Y.B Reddy, "Online Examination", Information Technology: New Generations 2008. ITNG 2008. Fifth International Conference on, pp. 1266-1267, 7-9 April 2008.

6) Schein, E. (1978). Career dynamics: matching individual and organizational needs. California: Addison-Wesley

7) Zahiru M. and Rahman M. (2013), "Online Examination System In Bangladesh Context". International Journal of Science, Environment ISSN 2278-3687 (O) and Technology, Vol. 2, No $3,2013,351-359$.

8) https://www.javatpoint.com/php-tutorial

9) https://www.w3schools.com/ 